\title{
Standing balance on inclined surfaces with different friction
}

\author{
Ingrid SVENSSON ${ }^{1}$, Chuansi GAO ${ }^{2 *}$, Amitava HALDER ${ }^{2}$, \\ Gunvor GARD $^{3,4}$ and Måns MAGNUSSON ${ }^{5}$
}

\author{
${ }^{1}$ Department of Biomedical Engineering, Faculty of Engineering, Lund University, Sweden \\ ${ }^{2}$ Division of Ergonomics and Aerosol Technology, Department of Design Sciences, Faculty of Engineering, Lund \\ University, Sweden \\ ${ }^{3}$ Division of Physiotherapy, Department of Health Sciences, Faculty of Medicine, Lund University, Sweden \\ ${ }^{4}$ Department of Health Sciences, Luleå University of Technology, Sweden \\ ${ }^{5}$ Balance Laboratory, Division of Otorhinolaryngology, Department of Clinical Sciences, Faculty of Medicine, \\ Lund University, Sweden
}

Received January 6, 2018 and accepted February 15, 2018

Published online in J-STAGE March 3, 2018

\begin{abstract}
Working and walking environments often involve standing positions on different surfaces with inclination and different friction. In this study, standing balance of thirteen participants during sudden and irregular external perturbation to calf muscles was investigated. The aim of the study was to evaluate the combined effect of surface inclination and friction on standing balance. The main findings when eyes closed revealed that the standing utilised coefficient of friction $\left(\mu_{\mathrm{SUCOF}}\right)$ increased when the surface was inclined for both high and low friction materials. The anteriorposterior torque increased more anteriorly when the surface was inclined toes down and when the surface friction was low. The results indicate that the anterior-posterior torque is a sensitive parameter when evaluating standing balance ability and slip risk. On inclined surface, particularly on the surface with lower friction, the potential slip and fall risk is higher due to the increase of standing utilised coefficient of friction and increased forward turning torque.
\end{abstract}

Key words: Posture control, Slope, Utilised friction, Anterior-posterior torque, Slipping and falling risk

\section{Introduction}

Standing balance and sufficient friction between footwear and underfoot surface are important to maintain postural stability and to prevent slip and fall accidents in working and walking environments. According to statistics of US Department of Labour ${ }^{1}$, roof workers are one of the highest risk groups among those with fatal

*To whom correspondence should be addressed. E-mail: Chuansi.Gao@design.lth.se

(C)2018 National Institute of Occupational Safety and Health occupational injuries. Roofing work is exposed to elevation, often characterized by manual handling of heavy and bulky materials and physical work. It includes standing, walking, reaching, stooping, crouching, and kneeling on inclined and confined roof surfaces, on narrow planks, or along the edge of the roof. These postures and movements are risky and require good balance. Good balance is dependent on visual information, proprioception as well as tactile perception ${ }^{2-10)}$. Standing and walking balance is challenged on sloped surfaces ${ }^{6-8,11,12)}$. In the construction sector, workers frequently need to stand on flat or inclined surfaces, covered with roofing materials of varying friction 
(e.g. metals, felt, asphalt, bricks, tiles, scaffolds, plywood, or plank $)^{13)}$. Falls from roofs are a serious cause of both fatal and non-fatal injuries in the construction industry and even during leisure time while clearing snow from the roofs of residential single-family homes ${ }^{14,15)}$.

The most common primary reasons for falls were slips, trips and losses of balance ${ }^{14}$. The inclined surfaces increased the risk of slip and fall incidents due to potentially large shear forces at the shoe/floor interface ${ }^{14,16)}$, frictional properties of the support surface ${ }^{14)}$, and low friction induced by various contaminations such as precipitation, condensation, snow or ice ${ }^{14,15,17)}$. While there are numer-

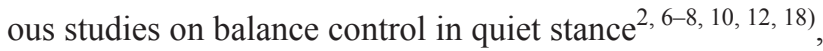
investigations on standing balance on inclined supporting surface materials in relation to induced perturbations and reduced friction are not well documented.

Few studies have investigated the effect of surface friction on balance while standing on a slope. The study by Keyserling et al. ${ }^{19)}$ showed that to prevent drivers from slipping while manoeuvering hand trucks down ramps it is necessary to select ramp surface treatments and shoe sole materials that provide sufficient friction for the task being performed. In another investigation, three support surface materials, Mocarbo rough tiles, patterned Isorel fibreboard and Teflon sheet with coefficient of friction (COF) being $0.59,0.42$ and 0.13 were used to study if dynamic postural mobility and performance are influenced when the risk of slipping is higher. The results showed that the friction contributes an essential element to the program of postural dynamics ${ }^{20)}$. A recent study revealed that the amplitude and duration of consecutive postural adjustments in single stepping is dependent on surface friction ${ }^{21)}$. A laboratory study on the effects of three factors: surface slope $\left(0^{\circ}, 18^{\circ}, 26^{\circ}\right.$, and $34^{\circ}$ ), elevated height ( 0 and $\left.3 \mathrm{~m}\right)$, and visual reference (with and without) on standing postural instability was performed by Simeonov et $a l^{7}$. However, only one type of surface material (plywood and painted with slip resistant paint) was used. This study, however, did not investigate the effect of slope and surface friction on standing balance, which can occur in winter and rainy seasons in many sectors.

Balance challenged by working and walking on an inclined surface for a longer time period has shown an increased postural sway ${ }^{8)}$. A recent study on the effects of surface inclination angle $\left(0,18\right.$ and $\left.26^{\circ}\right)$, standing direction (uphill, downhill, and lateral facing), and lumbar extensor fatigue on postural control during quiet standing showed that these three factors have negatively affected postural control, suggesting that working surfaces should be horizontal where possible ${ }^{22)}$. A similar study on balance control during standing on inclined surfaces showed that the isometric contraction in the ankle plantar flexor muscle increased as the slope inclined towards toes-town direction $^{23)}$. It has also been reported that the soleus muscle electromyography (EMG) increased in the condition toesdown (ankle plantar-flexion) ${ }^{24)}$.

The increased inclination, causing increased shear forces in combination with low surface friction could be important contributing factors to losing balance, and triggering slips and falls. There have been studies on standing balance on inclined surfaces, but the influence of surface material, friction and its interaction with inclination on balance control has not well been reported in the literature. Therefore, the objective of this study was to investigate the effect of the combination of surface available friction and inclination on standing balance and utilized friction.

\section{Methods}

\section{Participants}

Experiments were performed on thirteen healthy participants (eleven men and two women, mean age $27.9 \pm$ $4.2 \mathrm{yr}$, weight $78.6 \pm 7.5 \mathrm{~kg}$, height $1.79 \pm 0.04 \mathrm{~m}$ ). The participants had no neurological, musculoskeletal, balance or other disorders and were not on any form of medication. All participants had worked, studied or lived in the same city for more than two years, where the roads are usually slippery when covered with ice and snow in winter. Therefore, all participants had experience of standing and walking on slippery slopes. The study (AFA project no. 100026) was approved by the regional ethical review board in Lund, Sweden (EPN), and performed according to the Declaration of Helsinki for research involving human subjects. The participants signed informed consent before their participation in the study.

\section{Measurements}

Two vibrators were placed over the centre of the Gastrocnemius muscle belly on the right and left calf. The purpose of using vibrating perturbation was to perturb the balance of the participant and to evoke body sway while standing on a force platform. The perturbation technique made standing balance more challenging in laboratory settings. The forces and torques actuated by the feet were recorded with six degrees of freedom by the force platform connected to data acquisition system and software developed at the Balance Laboratory ${ }^{2}$. Data were sampled at $50 \mathrm{~Hz}$ by a computer equipped with an $\mathrm{AD}$ converter (Analogue Devices RTI-815). This method including the 


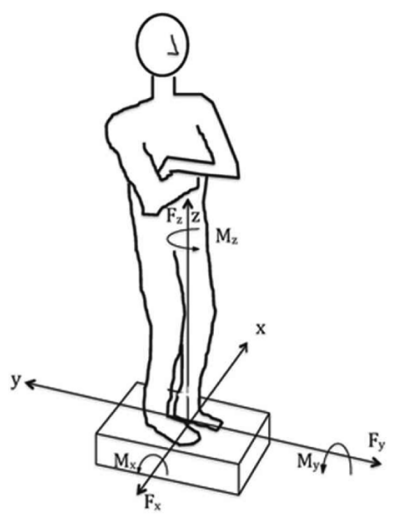

a)

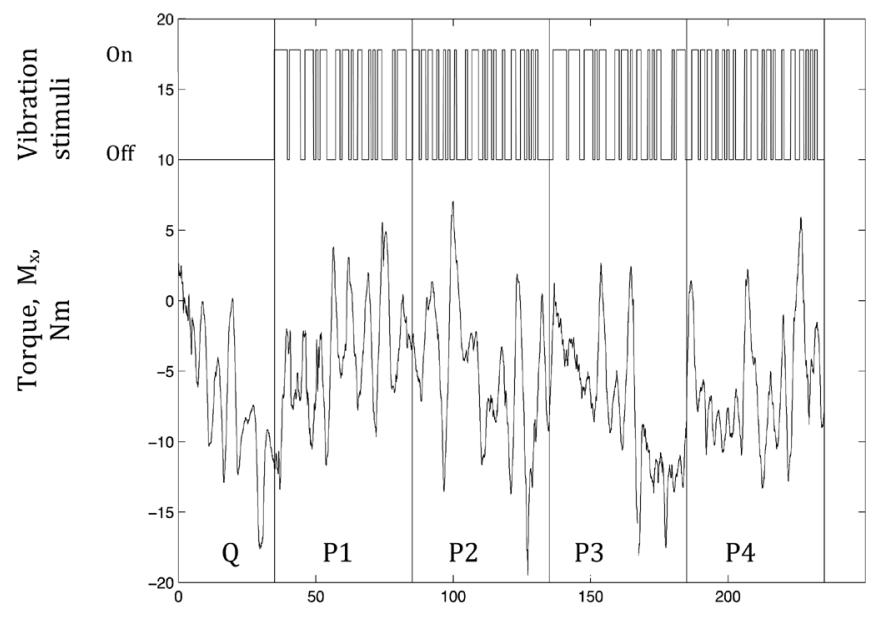

b)

Fig. 1. a) Schematic picture of the subject standing on the force platform. Note the definition of the positive directions for the three forces and torques that were measured. b) Example of data from the measurements: torque in the anterior posterior direction $\left(M_{x}\right)$ from one of the subjects standing on the horizontal surface covered by roofing felt with eyes closed. Note the division of the result in five time periods, $Q$ and P1-P4.

perturbation technique has been well described and used in a number of studies on human postural control ${ }^{2,25,26)}$.

\section{Test protocol}

The participants were asked to practise and familiarize with the test conditions prior to the real trials, and then were instructed to stand erect with their arms crossed over the chest and feet at an angle of about $30^{\circ}$ open in the front (Fig. 1a). The participants either focused on a mark on the wall at a distance of about $1.5 \mathrm{~m}$ or had their eyes closed. The head orientation maintained the same between eyes open and closed. Spontaneous postural sway in all three directions were recorded for the first $45 \mathrm{~s}$ of quiet stance (no vibration stimuli), after which the vibrators were turned on/off according to a computer controlled pseudorandom binary sequence (PRBS) schedule ${ }^{26}$, with a pulse time of 0.8-6.4 $\mathrm{s}$ for $200 \mathrm{~s}$ creating the same vibration stimuli for all test conditions and participants (Fig. 1b). The participant was standing on the balance plate for a total period of $245 \mathrm{~s}$ and the passage of events was divided into five periods, the first one Q - Quiet stance, 45 s without vibration stimuli and disturbance, followed by four periods (P1P4), each of which was $50 \mathrm{~s}$, (Fig. 1b). Two inclinations of the platform, horizontal (Hor) and $10 \%(\tan \alpha=0.1)$ which gave an angle of inclination of $5.7^{\circ}$, were used and two different surface materials covered the force platform. One covering material was polyoxymethylene plastic (POM) that was used to mimic a surface with low friction and the other was roofing felt (FELT) that gave a good grip, thus creating four test combinations $\left(1 . \mathrm{POM}_{\mathrm{Hor}}\right.$, 2. FELT $\mathrm{F}_{\mathrm{Hor}}$, 3. $\mathrm{POM}_{10 \%}, 4$. $\mathrm{FELT}_{10 \%}$ ). These two types of materials were chosen because they were used in previous investigations of actual slip resistance in non-contaminated surface conditions $^{26)}$. Each participant participated in eight tests in total since each participant performed two trials, one with eyes open, the other with eyes closed, in each of the four test conditions. The participants sat and rested for about 5 min between the tests, after which the participant was asked to stand at the same position and in the same direction (toes down in case on inclined surface) on the platform. The sequence between the different conditions and keeping eyes open or closed were randomized among the participants in order to minimize effect of habituation. All participants wore the same type of work shoes with nitrile rubber outsoles and deep treads. The same shoes were also used for the measurement of the COF. A test assistant was standing by the side of the participant to give support in case of loss of balance during the test.

The positive directions of the forces and torques measured by the balance platform were defined in Fig. 1a. Note that the anterior-posterior torque, $\mathrm{M}_{\mathrm{x}}$, affecting the platform was defined positive when the participant tilts backwards, while the medial-lateral torque, $\mathrm{M}_{\mathrm{y}}$, was positive when the participant was leaning to the right. The coordinate system was fixed to the balance plate and followed the plate when it was inclined. The balance plate was calibrated. Its reliability was tested in previous studies of standing postural sway ${ }^{2,25,28,29)}$. 


\section{Data analysis}

In order to reduce the influence of the body sizes of the participants, the forces from the three force measurements were normalized to the body mass and the torques were normalized to both the body mass and height of each individual participant. Each test was divided into five epochs (Q, P1P4) and, for each participant, linear mean values and variance over each specified period were calculated. Statistical analyses using a balanced two-way ANOVA were applied and followed by multiple comparisons between different test conditions. The difference was considered statistically significant if $p$-value was less than 0.05 and the statistical analyses were performed using the software MATLAB ${ }^{30)}$.

The available coefficient of friction between the same type of shoes and the two surface materials was measured in non-contaminated condition on a horizontal force plate according to the method used in a previous study ${ }^{27)}$. The measured available coefficient of friction (COF) was $\mu_{\mathrm{A}}=0.37$ for POM and $\mu_{\mathrm{A}}=0.49$ for roofing felt, both of which were lower than 0.50 that is recommended as the threshold for safe walking on level surfaces ${ }^{31)}$. No participant slipped during the balance tests. In order to evaluate the risk of slip, the utilised coefficient of friction during the test was calculated ${ }^{32)}$. The total friction force was derived from the test data through $F=\sqrt{F_{x}^{2}+F_{y}^{2}}$ and the standing utilised coefficient of friction $\left(\mu_{\mathrm{SUCOF}}\right)$ through dividing the frictional force by the vertical reaction force from the surface, $\mu_{S U C O F}=\frac{F}{F_{z}}$. The risk of slip increases when the value of the standing utilised friction approaches the value of the available friction ${ }^{33-36)}$.

The use of variance in the analysis of the torque data is motivated since the variance of the torque is independent of the tilt of the force plate and independent of possible small variations in the positions of the test persons standing on the force plate between the measurements. By integrating the square of the torque over the time of duration, it is shown that the variance of the torque is proportional to the energy consumed and the work performed by the ankle joint to maintain balance ${ }^{18,37)}$. The ratio of torques $\left(\mathrm{M}_{\mathrm{x}} / \mathrm{M}_{\mathrm{y}}\right)$ between the sagittal and lateral sway, is proportional to the power of the signal in different planes to maintain upright stance during perturbations.

\section{Results}

No significant differences were observed between the different conditions when the participants kept their eyes opened. The following results were from the tests when the eyes were closed. The standing utilised coefficient of friction increased when the surface was inclined. The increase compared to horizontal surface is shown in Fig. 2 for both the roofing felt and the POM surface. However, the available coefficient of friction of both POM and roofing felt is higher than the maximal standing utilised coefficient of friction on the inclined surfaces, indicating that the slip risk is small ${ }^{32-34)}$, although the risk is higher on POM than on the roofing felt.

The average amplitudes of variance of $M_{x}$ for all test persons in the four test conditions during the five epochs

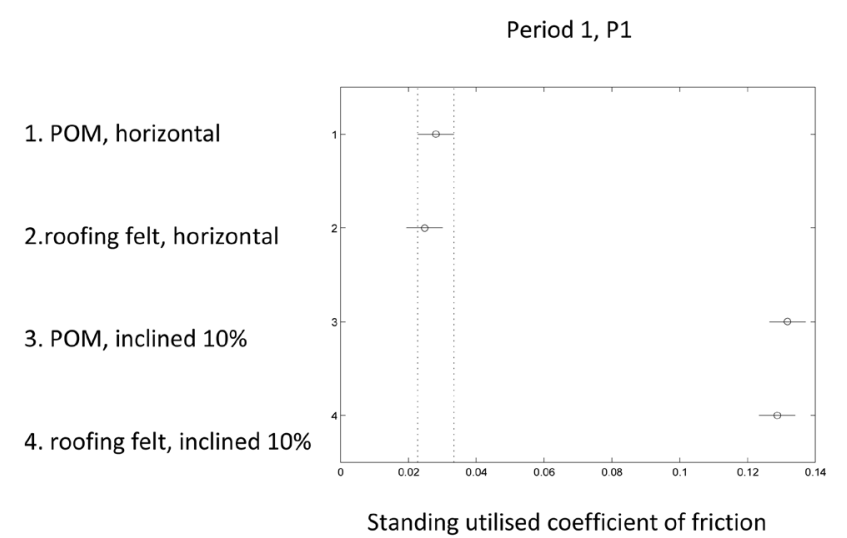

a)

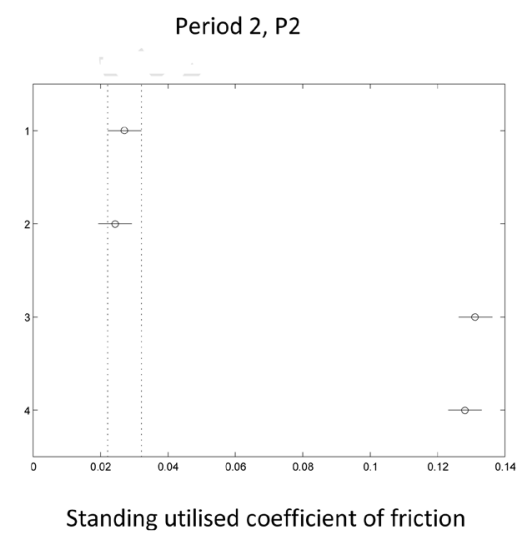

b)

Fig. 2. Comparison of the linear mean values of standing utilised coefficient friction, $\mu_{\text {SUCOF }}$, from data of the thirteen subjects with eyes closed: a) period 1 (P1) and b) period 2 (P2). The rings in the diagrams correspond to the linear mean value of all subjects in the study and each line corresponds to the interval. 
(Q, P1-4) are shown in Fig. 3a). No significant differences of the variance of $\mathrm{M}_{\mathrm{x}}$ were found between the test conditions. However, the variance of $\mathrm{M}_{\mathrm{x}}$ increased when the plate with the POM surface was inclined and over time (P4/P1, $\mathrm{POM}_{10 \%}>\mathrm{POM}_{\mathrm{Hor}}$ ) as shown in Table 1. The same differences were noted for the roofing felt but a significant difference was observed only for POM. The variance of the torque in the medial-lateral direction, $\mathrm{M}_{\mathrm{y}}$, was also observed. The trend was that the variance decreased when the plate was inclined for both surfaces but the effect of the inclination was significant only for the surface with lower friction ( $\mathrm{POM}_{\mathrm{Hor}}>\mathrm{POM}_{10} \%$ ) as in Fig. 3b).

The variance of the quotient between the torques $\left(\mathrm{M}_{\mathrm{x}} /\right.$ $M_{y}$ ) increased when the surfaces were inclined and over time (P4, $\mathrm{POM}_{10 \%}, \mathrm{FELT}_{10 \%}>\mathrm{POM}_{\mathrm{Hor}}$ ) as in Fig. 3c), the effect of the inclination was significant only for POM. If the variance of the fourth period was scaled by the variance of the first, the effect of the inclination became significant for the roofing felt $\left(\mathrm{P} 4 / \mathrm{P} 1, \mathrm{FELT}_{10 \%}>\mathrm{POM}_{\mathrm{Hor}}, \mathrm{FELT}_{\mathrm{Hor}}\right)$ as in Table 1.

\section{Discussion and Conclusion}

This study was mainly aimed at investigating the combined effect of available friction of surface materials and inclinations on standing balance and utilised coefficient of friction. The main findings revealed that on inclined surface, particularly on the surface material with lower friction, the potential slip and fall risk was higher due to the increase of standing utilised coefficient of friction and increased forward turning torque. No significant differences were observed between the different conditions when the participants kept their eyes opened. The inclination and surface friction effects were likely compensated by the visual stimuli. The standing balance was maintained within the limited inclination (10\%) and with present available coefficient of friction ( 0.37 and 0.49$)$ between the shoeunderfoot surface combinations for both eyes opened and closed. An earlier study comparing three conditions, including also toes-up (inclined backwards), showed that the control of the slow components of postural sway was more dependent on vision in similar conditions. Depending on the postural demand (inclination of the ramp), the proprioception was affected differently, indicating that there were both fast and slow mechanisms of balance control ${ }^{24)}$.

The increase of the utilised coefficient of friction when the surface was inclined was similar for both types of surface materials. The available coefficient of friction $\left(\mu_{\mathrm{A}}=0.37\right)$ was higher than the measured maximal stand-

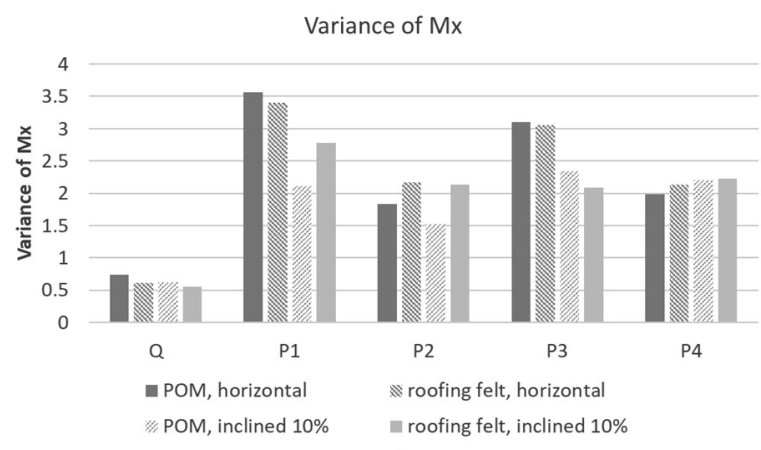

a)

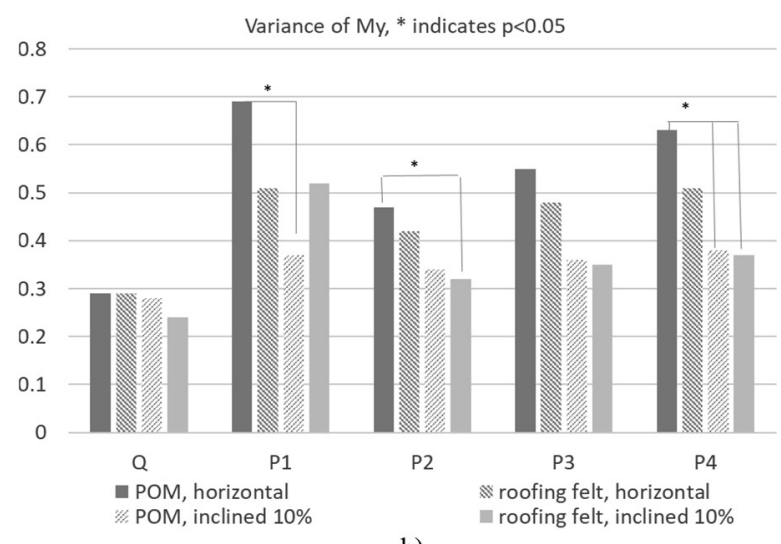

b)

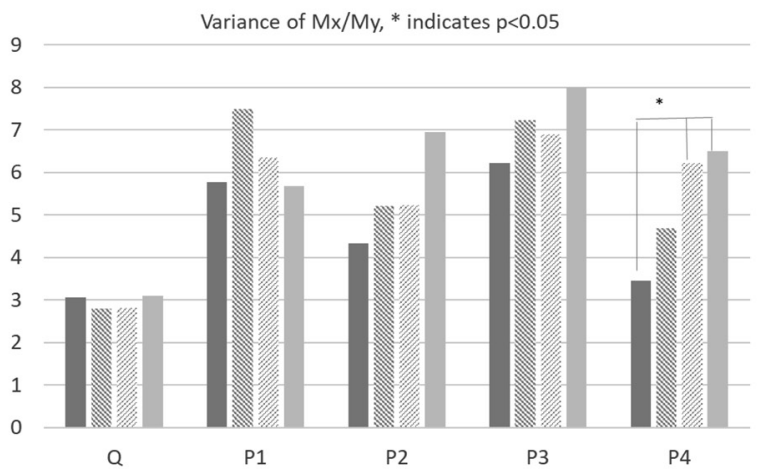

Fig. 3. Comparison of the variance of torque: a) mean variance of $M_{x}$, b) mean variance of $M_{y}$, c) mean variance of $M_{x} / M_{y}$. The values of the torques were normalized to the body mass and height of each participant.

ing utilised coefficient of friction $\left(\mu_{\mathrm{SUCOF}}=0.13\right)$ even on the POM surface. The study by Burnfield and Powers ${ }^{33)}$ showed that the risk for slip is very small when the available COF is about 0.077 higher than utilised COF and when the available COF is greater than 0.3. Although utilised coefficient of friction is within the boundary of the available COF, if more disturbances or distraction were to be added the risk of falling would be different. Furthermore, the slip risk could also be higher if more 
Table 1. The quotient between epochs 4 and 1 of the variance of $M_{x}, M_{y}$ and $M_{x} / M_{y}$

\begin{tabular}{|c|c|c|c|c|c|c|}
\hline \multirow[t]{2}{*}{$\begin{array}{l}\text { Variance of torque } \\
\text { (Eyes closed) }\end{array}$} & \multicolumn{2}{|c|}{$\begin{array}{c}\mathrm{P} 4 / \mathrm{P} 1 \\
\mathrm{M}_{\mathrm{x}} \\
\text { (Anterior/Posterior) }\end{array}$} & \multicolumn{2}{|c|}{$\begin{array}{c}\mathrm{P} 4 / \mathrm{P} 1 \\
\mathrm{M}_{\mathrm{y}} \\
\text { (Medial/Lateral) }\end{array}$} & \multicolumn{2}{|c|}{$\begin{array}{l}\mathrm{P} 4 / \mathrm{P} 1 \\
\mathrm{M}_{\mathrm{x}} / \mathrm{M}_{\mathrm{y}}\end{array}$} \\
\hline & $p$-value & Quotient & $p$-value & Quotient & $p$-value & Quotient \\
\hline POM, horizontal & 0.032 & $0.68^{*}$ & ns & 1.20 & 0.009 & $0.71 * *$ \\
\hline roofing felt, horizontal & ns & 0.81 & $\mathrm{~ns}$ & 1.22 & 0.022 & $0.80^{* *}$ \\
\hline POM, inclined $10 \%$ & 0.032 & $1.33^{*}$ & ns & 1.14 & ns & 1.34 \\
\hline roofing felt, inclined $10 \%$ & ns & 1.08 & ns & 0.72 & 0.022 & $1.64 * *$ \\
\hline
\end{tabular}

*The quotient of the variance of $\mathrm{M}_{\mathrm{x}}$ on POM and inclined 10\% is significantly higher than on horizontal POM. **The quotient of $\mathrm{M}_{\mathrm{x}} / \mathrm{M}_{\mathrm{y}}$ is significantly higher on roofing felt and inclined $10 \%$ than on horizontal roofing felt and horizontal POM.

slippery materials were used in either the shoe soles or underfoot surface. For example, the available coefficient of friction on melting ice $(0.06)$ could be much smaller ${ }^{17,38)}$ than those on the two surfaces tested, and smaller than the utilised COF obtained in present study. Therefore, to maintain standing balance on icy roofs is very difficult and slip and fall risks are extremely high.

In comparison to forces, torque variance is more relevant in keeping the standing person from falling ${ }^{2,24)}$. In the present study when the surface was inclined forward, the mean anterior-posterior torque $\left(\mathrm{M}_{\mathrm{x}}\right)$ decreased. But the effect was significant only on the surface with lower friction. Although the standing balance of all participants was maintained during the whole test period and the slip risk was very small, the anterior-posterior torque was affected, namely by turning forwards, when the surface was inclined forwards and when the available friction was smaller. This may indicate that the anterior-posterior torques is a sensitive parameter for the evaluation of standing balance ability and fall risk. This result is consistent with the finding from the study by Simeonov et $a l .{ }^{7)}$ where the increase of surface slope resulted in a progressive increase of anterior-posterior centre of pressure displacement. The comparison of sway velocity in the anterior-posterior and medial-lateral directions revealed that slope had considerably larger effects on the sway velocity components in anterior-posterior direction $\left(\mathrm{V}_{\mathrm{AP}}\right)$ than on the mediallateral direction $\left(\mathrm{V}_{\mathrm{ML}}\right)$. The ratio $\mathrm{V}_{\mathrm{AP}} / \mathrm{V}_{\mathrm{ML}}$ increased with slope, revealing a directional effect of slope on balance ${ }^{7)}$.

The variance of the anterior-posterior torque increased when the plate was inclined and when the participant stood on the surface for a longer period of time (P4/ $\mathrm{P} 1)$, especially for the surface with lower friction. In the study of exposing the participants for $20 \mathrm{~min}$ to $2 \mathrm{~h}$ on an inclined surface $\left(26^{\circ}\right)$, Wade and Davis ${ }^{8)}$ found that standing posture on a level surface was less stable directly after the exposure on the inclined surface. The variance of the torque was higher during P4 than that during P1 could be an effect of muscle fatigue caused by four minutes of standing still. In the present study, the total standing period was longer than those reported in the literature ${ }^{8,29,39)}$. The magnitudes of the postural sway obtained in some of the studies, where the authors induced muscle fatigue using repetitive toe-lift exercise until exhaustion or similar fatiguing pre-exercise, after which the standing balance was measured on a level force plate ${ }^{29,39)}$ could be higher than that in the present study since the intensity of the induced muscle fatigue prior to the balance test was much greater.

The variance of the torque in the medial-lateral direction $\left(\mathrm{M}_{\mathrm{y}}\right)$ decreased when the plate was inclined for almost all periods of stimulations. This difference was observed for both surfaces but it was even clearer for the surface with lower friction (POM).

The variance of the quotient between the torques $\left(\mathrm{M}_{\mathrm{x}} /\right.$ $\mathrm{M}_{\mathrm{y}}$ ) increased for the inclined surface over time (P4 and $\mathrm{P} 4 / \mathrm{P} 1)$. This may indicate that more energy is needed while maintaining standing balance in the sagittal plane when the surface is inclined in the same direction and this is more obvious in late standing period. The findings of a change e.g. increase in sway variance reflects that more effort is required to maintain posture under these conditions. All differences in postural sway are more obvious for the surface with lower friction. This could be understood as low friction being a risk factor to challenge standing balance. Some differences are more apparent over longer time periods. This result seems to be consistent with the findings by Wade and Davis ${ }^{8)}$ although they investigated the standing postural sway after longer time ( $20 \mathrm{~min}-2 \mathrm{~h}$ ) exposure to a steeper slope prior to balance test than the $245 \mathrm{~s}$ standing during balance test in the present study.

The present study has limitations. Firstly, all participants were young and healthy and the total number of participants 
$(n=13)$, and especially the number of female participants $(n=2)$, was limited. Only two angles were used for the inclination (level and 10\%) in this pilot study. Although the inclination was not much as compared to more inclined roofs, $10 \%$ inclination is a challenge for pedestrians walking on slippery sidewalks, particularly in icy and snowy winter conditions. This preliminary laboratory study was performed on non-contaminated surfaces. The differences of the available coefficients of friction were relatively small. More challenging inclinations and slippery surfaces should be further investigated. The study was conducted when the participants were standing, not walking. We believe that understanding standing balance ability is fundamental and critical for dynamic stability, which should be investigated in further studies, e.g. during walking on more slippery and inclined surfaces. In normal conditions the surface under the feet provides sufficient support and friction. The effects of inclination on the risk of falls under real work conditions have been observed and evaluated in an investigation of reported falls in postal delivery workers ${ }^{40)}$. According to the observation $30 \%$ of the falls occurred when walking down a slope compared to $2 \%$ when walking up.

In conclusion, when eyes closed, on flat surface, there is a significant reduction of the effort used to maintain stance, reflected in a reduction of body sway over time. The standing utilised coefficient of friction ( $\mu \mathrm{SUCOF}$ ) increased when the surface was inclined for both high and low friction materials. The anterior-posterior torque increased more anteriorly when the surface was inclined toes down and when the surface friction was low. The variance of the quotient between the torques $\left(\mathrm{M}_{\mathrm{X}} / \mathrm{M}_{\mathrm{y}}\right)$ increased on inclined surface over time (P4 and P4/P1). The findings of a change e.g. increase in sway variance reflects that more effort is required to maintain posture under these conditions. The results indicate that the anterior-posterior torque is a sensitive parameter when evaluating standing balance ability and slip risk.

On flat surface, there is a significant reduction of the effort used to maintain stance, reflected in a reduction of body sway over time. In the context of inclined surface or reduced friction, this adaption revealed in the $\mathrm{P} 4 / \mathrm{P} 1$ indicates a reduced ability to adapt. This implies that more energy and force are needed to maintain upright posture in such conditions when eyes closed and that the safety margin to a loss of balance is reduced although the utilised coefficient of friction is still within the available friction. Such findings can help to understand biomechanical mechanisms and prevent slip and fall accidents and injuries in working and walking environments.

A systems approach to factors that challenge postural control in the context of everyday situations and especially working and walking environments should be further developed and applied not only to workers in construction, health care, post-delivery and transport services, but also to the disabled, the elderly and other frequent fallers.

\section{Acknowledgements}

The authors are grateful to the subjects for their participation in the study, to Per-Anders Fransson for help with the recordings, and to Michael Miller for language editing.

\section{Funding}

This work was financially supported by AFA Insurance (project no. 100026).

\section{Conflict of interest}

None.

\section{References}

1) Bureau of Labor Statistics (BLS) 2017. National Census of Fatal Occupational Injuries in 2016, News Release, US Department of Labor, BLS, Washington, DC. http://www. bls.gov/news.release/pdf/cfoi.pdf. Accessed January 5, 2018.

2) Fransson P, Magnusson M, Johansson R (1998) Analysis of adaptation in anteroposterior dynamics of human postural control. Gait Posture 7, 64-74. [Medline] [CrossRef]

3) Mergner $T$, Rosemeier $T$ (1998) Interaction of vestibular, somatosensory and visual signals for postural control and motion perception under terrestrial and microgravity conditions - a conceptual model. Brain Res Brain Res Rev 28, 118-35. [Medline] [CrossRef]

4) Grönqvist R, Abeysekera J, Gard G, Hsiang SM, Leamon TB, Newman DJ, Gielo-Perczak K, Lockhart TE, Pai CYC (2001) Human-centred approaches in slipperiness measurement. Ergonomics 44, 1167-99. [Medline] [CrossRef]

5) Gauchard G, Chau N, Mur JM, Perrin P (2001) Falls and working individuals: role of extrinsic and intrinsic factors. Ergonomics 44, 1330-9. [Medline] [CrossRef]

6) Leroux A, Fung J, Barbeau H (2002) Postural adaptation to walking on inclined surfaces: I. Normal strategies. Gait Posture 15, 64-74. [Medline] [CrossRef]

7) Simeonov PI, Hsiao H, Dotson BW, Ammons DE (2003) Control and perception of balance at elevated and sloped surfaces. Hum Factors 45, 136-47. [Medline] [CrossRef]

8) Wade C, Davis J (2009) Postural sway following prolonged exposure to an inclined surface. Saf Sci 47, 652-8. 
[CrossRef]

9) Wall C 3rd, Wrisley DM, Statler KD (2009) Vibrotactile tilt feedback improves dynamic gait index: a fall risk indicator in older adults. Gait Posture 30, 16-21. [Medline] [CrossRef]

10) Garkavenko VV, Gorkovenko AV, Kolosova EV, Korneyev VV, Mel'nichouk AV, Vasilenko DV (2012) Modifications of the stabilogram during upright standing posture under conditions of inclines of the support surface. Neurophysiology 44, 131-7. [CrossRef]

11) Sun J, Walters M, Svensson N, Lloyd D (1996) The influence of surface slope on human gait characteristics: a study of urban pedestrians walking on an inclined surface. Ergonomics 39, 677-92. [Medline] [CrossRef]

12) Wade C, Davis J, Weimar WH (2014) Balance and exposure to an elevated sloped surface. Gait Posture 39, 599-605. [Medline] [CrossRef]

13) Byggindustrins Centrala ArbetsmiljörÅd (BCA) 2007:1. Arbetsskador i byggverksamhet 2006.

14) Hsiao H, Simeonov P (2001) Preventing falls from roofs: a critical review. Ergonomics 44, 537-61. [Medline] [CrossRef]

15) Bylund PO, Johansson J, Albertsson P (2016) Injuries sustained during snow removal from roofs resulting in hospital care. Int J Inj Contr Saf Promot 23, 105-9 [CrossRef]. [Medline]

16) Redfern MS, DiPasquale J (1997) Biomechanics of descending ramps. Gait Posture 6, 119-25. [CrossRef]

17) Gao C, Abeysekera J, Hirvonen M, Aschan C (2003) The effect of footwear sole abrasion on the coefficient of friction on melting and hard ice. Int J Ind Ergon 31, 323-30. [CrossRef]

18) Magnusson M, Johansson R, Wiklund J (1990) Galvanically induced body sway in the anterior-posterior plane. Acta Otolaryngol 110, 11-7. [Medline] [CrossRef]

19) Keyserling WM, Monroe KA, Woolley CB, Ulin SS (1999) Ergonomic considerations in trucking delivery operations: an evaluation of hand trucks and ramps. Am Ind Hyg Assoc J 60, 22-31 [CrossRef].

20) Gaudez C, Le Bozec S, Richardson J (2004) Does support surface coefficient of friction influence postural dynamics and isometric force productions of the upper extremities performed by seated subjects? Neurosci Lett 366, 245-9. [Medline] [CrossRef]

21) Memari S, Le Bozec S, Bouisset S (2014) Particular adaptations to potentially slippery surfaces: the effects of friction on consecutive postural adjustments (CPA). Neurosci Lett 561, 24-9. [Medline] [CrossRef]

22) Lin D, Nussbaum MA (2012) Effects of lumbar extensor fatigue and surface inclination on postural control during quiet stance. Appl Ergon 43, 1008-15. [Medline] [CrossRef]

23) Sasagawa S, Ushiyama J, Masani K, Kouzaki M, Kanehisa H (2009) Balance control under different passive contributions of the ankle extensors: quiet standing on inclined surfaces. Exp Brain Res 196, 537-44. [Medline] [CrossRef]

24) Mezzarane RA, Kohn AF (2007) Control of upright stance over inclined surfaces. Exp Brain Res 180, 377-88. [Medline] [CrossRef]

25) Fransson P, Johansson R, Hafström A, Magnusson M (2000) Methods for evaluation of postural control adaptation. Gait Posture 12, 14-24. [Medline] [CrossRef]

26) Johansson R (1993) System modelling and identification. Englewood Cliffs, Prentice Hall.

27) Gao C, Svensson I, Kuklane K (2014) Actual slip resistance of shoes worn by visitors in a national exposition-Gilla Jobbet. 6th European Conference on Protective Clothing, 14-16 May, Bruges, Belgium.

28) Johansson R, Magnusson M, Fransson PA, Karlberg M (2001) Multi-stimulus multi-response posturography. Math Biosci 174, 41-59. [Medline] [CrossRef]

29) Ledin T, Fransson PA, Magnusson M (2004) Effects of postural disturbances with fatigued triceps surae muscles or with 20\% additional body weight. Gait Posture 19, 184-93. [Medline] [CrossRef]

30) MATLAB Version 7.12.0.635 (R2011a), ${ }^{\circ} 1984-2011$ The MathWorks, Inc.

31) ANSI (2001) Standard for the provision of slip resistance on walking/working surfaces (A1264.2-2001). ANSI, Washington, DC.

32) Hanson JP, Redfern MS, Mazumdar M (1999) Predicting slips and falls considering required and available friction. Ergonomics 42, 1619-33. [Medline] [CrossRef]

33) Burnfield JM, Powers CM (2006) Prediction of slips: an evaluation of utilized coefficient of friction and available slip resistance. Ergonomics 49, 982-95. [Medline] [CrossRef]

34) Chang WR (2004) A statistical model to estimate the probability of slip and fall incidents. Saf Sci 42, 779-89. [CrossRef]

35) Chang WR, Chang CC, Matz S (2011) The effect of transverse shear force on the required coefficient of friction for level walking. Hum Factors 53, 461-73. [Medline] [CrossRef]

36) Redfern MS, Cham R, Gielo-Perczak K, Grönqvist R, Hirvonen M, Lanshammar H, Marpet M, Pai CYC, Powers C (2001) Biomechanics of slips. Ergonomics 44, 1138-66. [Medline] [CrossRef]

37) Åkesson M, Magnusson M, Johansson R (1988) Identification of human postural dynamics. IEEE Trans. Biomed Eng (NY) 3, 858-69.

38) Gao C, Abeysekera J, Hirvonen M, Grönqvist R (2004) Slip resistant properties of footwear on ice. Ergonomics 47, 710-6. [Medline] [CrossRef]

39) Vuillerme N, Burdet C, Isableu B, Demetz S (2006) The magnitude of the effect of calf muscles fatigue on postural control during bipedal quiet standing with vision depends on the eye-visual target distance. Gait Posture 24, 169-72. [Medline] [CrossRef]

40) Haslam RA, Bentley TA (1999) Follow-up investigations of slip, trip and fall accidents among postal delivery workers. Saf Sci 32, 33-47. [CrossRef] 